\title{
Benzpyrimoxan: Design, synthesis, and biological activity of a novel insecticide
}

\author{
Eikoh Satoh,* Ryota Kasahara, Kosuke Fukatsu, Takao Aoki, Hiroto Harayama and Tetsuya Murata \\ Research Center, Research Division, Nihon Nohyaku Co., Ltd., 345 Oyamada-cho, Kawachi-nagano, Osaka 586-0094, Japan
}

(Received October 29, 2020; Accepted December 17, 2020)

Benzpyrimoxan (5-(1,3-dioxan-2-yl)-4-\{[4-(trifluoromethyl)phenyl]methoxy\}pyrimidine, NNI1501) was discovered as a novel insecticide structurally characterized by a pyrimidine derivative substituted with 1,3-dioxanyl and 4-trifluoromethylbenzyloxy groups. The compound showed remarkable activity against nymphs of rice planthoppers, including strains resistant to existing insecticides. Furthermore, benzpyrimoxan had low adverse effects on pollinators and beneficial arthropods. Because of these features, benzpyrimoxan is expected to be a suitable part of an integrated pest management strategy. In this report, the history of the discovery to reach benzpyrimoxan and details of the structure-activity relationships are described.

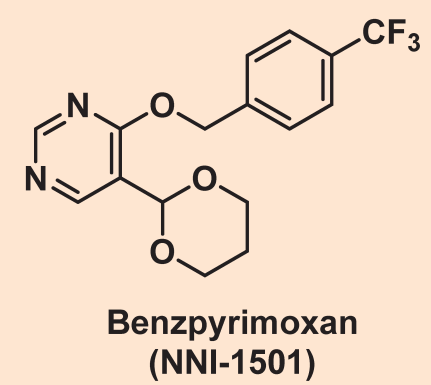

Keywords: benzpyrimoxan, NNI-1501, insecticide, rice planthoppers, insect growth regulator, integrated pest management.

\section{Introduction}

Rice is an essential staple food crop for feeding the almost half of the world population and is cultivated mainly in Japan, India, China, and Southeast Asia. To obtain high yields of rice, it must be protected from various pests. The rice planthoppers are one of the most serious pest insects, causing huge economic damage. In particular, the brown rice planthopper (BPH, Nilaparvata lugens) causes hopper burn, which significantly reduces the rice yield. Moreover, BPH has developed resistance to existing insecticides and has become difficult to control in the paddy field. Therefore, new active ingredients with a novel mode of action for control of BPH are needed.

Heterocycles have often been incorporated into numerous natural products, pharmaceuticals, agricultural chemicals, and so on. Pyridine and pyrimidine rings particularly have drawn strong attention because they have been widely used in agricul-

\footnotetext{
* To whom correspondence should be addressed.

E-mail: satoh-eikoh@nichino.co.jp

Published online January 27, 2021
}

(c) BY-NC-ND $\odot$ Pesticide Science Society of Japan 2021. This is an open access article distributed under the Creative Commons Attribution-NonCommercial-NoDerivatives 4.0 International (CC BY-NC-ND 4.0) License (https://creativecommons.org/licenses/by-nc-nd/4.0/) tural chemicals. Furthermore, these heterocycles are known to be integrated into a large number of insecticides such as flonicamid $^{1)}$ and the compounds listed in the patent ${ }^{2)}$ shown in Fig. 1. We became interested in pyridine and pyrimidine rings and started studying to create a new insecticide containing these rings. As shown in Fig. 1, pyrimidine derivative $\mathbf{1}$ was discovered by exploring various compounds with reference to these heterocyclic derivatives and was found to exhibit insecticidal activity against $\mathrm{BPH}$ nymphs at the time of molting. We attempted modification of the substituents on the pyrimidine ring of compound $\mathbf{1}$ and found compound $\mathbf{2 a}$. Compound $\mathbf{2 b}$, which showed high insecticidal activity, was discovered as a lead compound by converting of the substituents on the phenyl ring of compound 2a. Investigation of various biological assays for compound $\mathbf{2} \mathbf{b}$ revealed that the residual efficacy of $\mathbf{2} \mathbf{b}$ against $\mathrm{BPH}$ was inferior to that of buprofezin, ${ }^{3)}$ which is known as an insect growth regulator (IGR). In order to improve the residual efficacy, the substituents of formula 3 were optimized, which finally led to the identification of benzpyrimoxan ${ }^{4,5)}$ (Fig. 1). It had the most favorable properties due to its high insecticidal activity and its low adverse effects on natural enemies and honeybees. These features of the novel insecticide were suitable for use in an integrated pest management (IPM) strategy. 


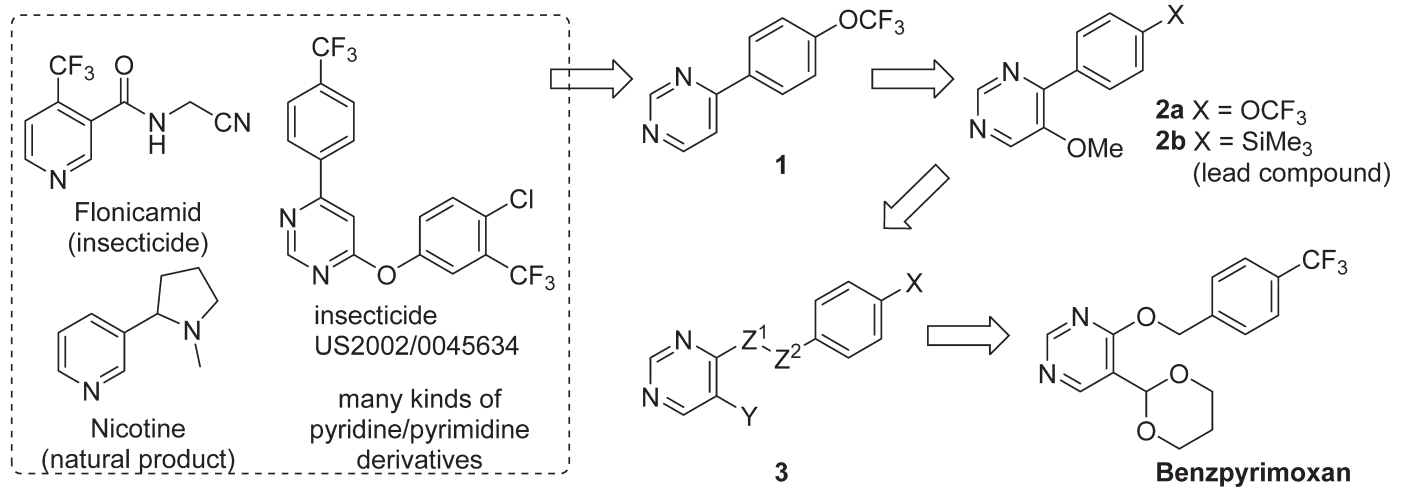

Fig. 1. Discovery of benzpyrimoxan.

\section{Materials and methods}

\section{Preparation of compounds}

Chemical structures were confirmed by ${ }^{1} \mathrm{H}-\mathrm{NMR}$ and ${ }^{13} \mathrm{C}-\mathrm{NMR}$ spectroscopy using a Bruker ARX-400 NMR spectrometer with tetramethylsilane as an internal standard. Melting points were measured with a Mettler FP80 melting point apparatus and uncorrected.

\subsection{Synthesis}

The synthetic pathway of benzpyrimoxan is shown in Scheme 1. 4,6-Dichloro-5- (1,3-dioxan-2-yl)pyrimidine (5) was obtained by the Vilsmeier-Haack reaction of 4,6-dihydroxypyrimidine (4) followed by the reaction with 1,3-propanediol. 4-Trifluoromethylbenzyloxy group was introduced into pyrimidine intermediate $\mathbf{5}$ and the chlorine group of 4-trifluoromethylbenzyloxy pyrimidine derivative 6 was reduced to give benzpyrimoxan. ${ }^{6)}$

1.2. 4,6-dichloro-5-(1,3-dioxan-2-yl)pyrimidine (5)

$\mathrm{N}, \mathrm{N}$-dimethyl formamide $(15.0 \mathrm{~g}, 130 \mathrm{mmol})$ was slowly added to phosphorus oxychloride $(103 \mathrm{~g}, 670 \mathrm{mmol})$ at $0^{\circ} \mathrm{C}$ and stirred at room temperature for $10 \mathrm{~min}$. The mixture was added with 4,6-dihydroxypyrimidine $(4)$ at $0^{\circ} \mathrm{C}$ and stirred at $90^{\circ} \mathrm{C}$ for $3 \mathrm{hr}$. Excess of phosphorus oxychloride was removed under reduced pressure and the residue was poured into ice water and extracted with chloroform. The organic layer was washed with an aqueous sodium hydrogen carbonate solution and brine, and dried over anhydrous magnesium sulfate. The solvent was removed under reduced pressure to give 4,6-dichloro-5-formylpyrimidine ( $14.0 \mathrm{~g}, 59 \%$ yield). The crude compound was used for the next reaction without further purification.

To a solution of 4,6-dichloro-5-formylpyrimidine (5.6 g, $32 \mathrm{mmol})$ in toluene $(50 \mathrm{~mL}), 1,3$-propanediol $(4.8 \mathrm{~g}, 63 \mathrm{mmol})$ and $p$-toluenesulfonic acid monohydrate $(0.60 \mathrm{~g}, 3.2 \mathrm{mmol})$ was added at room temperature. The reaction mixture was refluxed for $1 \mathrm{hr}$ with a dean-stark apparatus to remove water. The mixture was diluted with ethyl acetate, followed by washing with an aqueous sodium hydrogen carbonate solution and brine. The organic layer was dried over anhydrous magnesium sulfate and concentrated in vacuo. The residue was chromatographed on a silicagel column to give 4,6-dichloro-5-(1,3-dioxan-2-yl)pyrimidine (5) $(5.1 \mathrm{~g}, 67 \%$ yield) as a white crystal. m.p. 122$125^{\circ} \mathrm{C} .{ }^{1} \mathrm{H}-\mathrm{NMR}\left(\mathrm{CDCl}_{3}\right) \delta \mathrm{ppm}: 8.71(\mathrm{~s}, 1 \mathrm{H}), 6.12(\mathrm{~s}, 1 \mathrm{H}), 4.30$ (ddd, 1H), 3.98 (ddd, 1H), 2.41-2.28 (m, 1H), 1.49-1.45 (m, $1 \mathrm{H})$.

1.3. 6-chloro-5-(1,3-dioxan-2-yl)-4-\{[4-(trifluoromethyl)phenyl]methoxy\} pyrimidine (6)

To a solution of compound $5(1.0 \mathrm{~g}, 4.3 \mathrm{mmol})$ and 4-trifluoromethylbenzyl alcohol $(0.82 \mathrm{~g}, 4.7 \mathrm{mmol})$ in $N, N$-dimethyl acetamide $(5.0 \mathrm{~mL}), 60 \%$ sodium hydrate $(0.20 \mathrm{~g}, 5.1 \mathrm{mmol})$ was added at $0^{\circ} \mathrm{C}$ and stirred at room temperature for $2 \mathrm{hr}$. The reaction mixture was poured into ice water and extracted with ethyl acetate. The extract was washed with brine and dried over anhydrous magnesium sulfate. The organic layer was concentrated in vacuo and the residue was purified by silica gel chromatography to give 6-chloro-5-(1,3-dioxan-2-yl)-4-\{[4-(trifluoromethyl)phenyl]methoxy\}pyrimidine (6) (1.1 g, 69\% yield) as a colorless crystal. m.p. ${ }^{114}-115^{\circ} \mathrm{C} .{ }^{1} \mathrm{H}-\mathrm{NMR}\left(\mathrm{CDCl}_{3}\right) \delta \mathrm{ppm}: 8.50(\mathrm{~S}, 1 \mathrm{H})$, 7.66-7.60 (m, 4H), 6.05 (s, 1H), 5.57 (s, 2H), 4.27 (ddd, 1H), 3.98 (ddd, $1 \mathrm{H}), 2.32-2.23(\mathrm{~m}, 1 \mathrm{H}), 1.54-1.44(\mathrm{~m}, 1 \mathrm{H})$.

1.4. 5-(1,3-dioxan-2-yl)-4-\{[4-(trifluoromethyl)phenyl]methoxy\}pyrimidine (benzpyrimoxan)

To a solution of compound $6(1.1 \mathrm{~g}, 2.9 \mathrm{mmol})$, triethylamine $(0.65 \mathrm{~g}, 6.5 \mathrm{mmol})$ and formic acid $(0.27 \mathrm{~g}, 5.9 \mathrm{mmol})$ in $\mathrm{N}, \mathrm{N}$ dimethyl acetamide $(5.0 \mathrm{~mL})$, tetrakis (triphenylphosphine) palladium (0) $(0.34 \mathrm{~g}, 0.29 \mathrm{mmol})$ was added and stirred at $80^{\circ} \mathrm{C}$ for

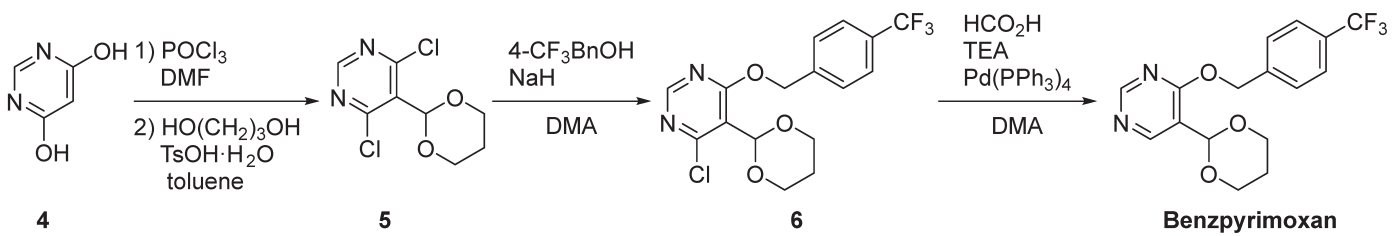

Scheme 1. Synthetic pathways of benzpyrimoxan. 
$1.5 \mathrm{hr}$ under argon atmosphere. The reaction mixture was added with water and extracted with tert-butyl methyl ether, followed by washing with water and brine. The organic layer was concentrated in vacuo and the residue was purified by silica gel chromatography to give benzpyrimoxan $(0.81 \mathrm{~g}, 81 \%$ yield $)$ as a pale yellowish crystal. m.p. $120.1-121.3{ }^{\circ} \mathrm{C} .{ }^{13} \mathrm{C}-\mathrm{NMR}$ (DMSO- $d_{6}$ ) $\delta$ ppm: 164.9, 158.2, 154.8, 141.2, $128.3\left(\mathrm{q}, J_{C-F}=32 \mathrm{~Hz}\right), 127.6$, $125.3\left(\mathrm{q}, J_{C-F}=4 \mathrm{~Hz}\right), 124.2\left(\mathrm{q}, J_{C-F}=272 \mathrm{~Hz}\right), 118.9,95.0,66.8$, 66.5, 25.2. ${ }^{1} \mathrm{H}-\mathrm{NMR}\left(\mathrm{CDCl}_{3}\right) \delta \mathrm{ppm}: 8.75(\mathrm{~s}, 1 \mathrm{H}), 8.74(\mathrm{~s}, 1 \mathrm{H})$, $7.64(\mathrm{~d}, 2 \mathrm{H}), 7.55(\mathrm{~d}, 2 \mathrm{H}), 5.77(\mathrm{~s}, 1 \mathrm{H}), 5.55(\mathrm{~s}, 2 \mathrm{H}), 4.27$ (ddd, $1 \mathrm{H}), 3.99$ (ddd, $1 \mathrm{H}), 2.32-2.19(\mathrm{~m}, 1 \mathrm{H}), 1.49-1.44(\mathrm{~m}, 1 \mathrm{H})$. Water solubility: $5.04 \mathrm{mg} / \mathrm{L}\left(20^{\circ} \mathrm{C}\right)$. Partition coefficient $\log P_{\mathrm{o} / \mathrm{w}}$ : $3.42\left(25^{\circ} \mathrm{C}\right)$

\subsection{Other derivatives}

The other derivatives were synthesized in a similar way, and commercially available reagents and solvents were used unless otherwise noted.

\section{Biological assay}

\subsection{Rice planthoppers}

An insecticide-susceptible strain of the BPH was collected from a rice field in Wakayama Pref., Japan, in 1983 and maintained at the Research Center, Nihon Nohyaku Co., Ltd., using rice seedlings Oryza sativa L., as feed without any insecticidal or acaricidal treatment under the following conditions: $25 \pm 1^{\circ} \mathrm{C}$, $60-70 \%$ R.H., and a $16 \mathrm{~L}$ : $8 \mathrm{D}$ photoperiod.

\subsection{Rice seedling assay}

To investigate the insecticidal activity of candidate compounds against $\mathrm{BPH}$, rice seedlings were cultivated in a paper pot the 2.0-2.5 leaf stage in a greenhouse as a test crop. The candidate compound was formulated in $10 \%(\mathrm{w} / \mathrm{w}) \mathrm{EC}$, and test solutions of the compound at various concentrations $(0.03,0.1,0.3,1,3$, $10,30 \mathrm{mg}$ a.i./L) were prepared by diluting an EC formulation with water containing a wetting agent (Mai-Rinoh $\left.{ }^{\circledR}, 0.1 \mathrm{~mL} / \mathrm{L}\right)$. Those of the reference compound were prepared similarly with a commercial product, buprofezin 25\% WP (Applaud ${ }^{\circledR}$ ). Control plots were treated with water containing the wetting agent. The leaf sheaths and leaves of rice seedlings were dipped in a test solution for $30 \mathrm{sec}$ and allowed to dry. The treated seedlings were placed in a glass tube $20 \mathrm{~cm}$ long, and ten nymphs of the third instar $\mathrm{BPH}$ were inoculated onto the treated seedlings. The treated insects were maintained at $25 \pm 1^{\circ} \mathrm{C}, 60-70 \%$ R.H., and a 16L : 8D photoperiod. Each treatment consisted of two replicates. The surviving nymphs and adults were counted 7 days after treatment. Biological activity was expressed using the corrected mortality (\%), which was calculated according to the formula shown below.

\section{Corrected mortality $(\%)=(N c-N t) / N c \times 100$}

where $N c$ is the number of survivals at the control plot and $N t$ is the number of survivals at the treatment plot.

\subsection{Greenhouse test (residual efficacy)}

To check the residual efficacy of candidate compounds against $\mathrm{BPH}, 6-7$ of the rice seedlings were transplanted to soil in a
$2 \mathrm{~L}$ plastic pot and then maintained inside a greenhouse until the 6-7 leaf stage as a test crop. The candidate compound was formulated in $10 \%(\mathrm{w} / \mathrm{w}) \mathrm{EC}$, and the test solution of the compound at $100 \mathrm{mg}$ a.i./L was prepared by diluting an EC formulation with water containing a wetting agent (Mai-Rinoh ${ }^{\circledR}$, $0.1 \mathrm{~mL} / \mathrm{L})$. That of the reference compound at $125 \mathrm{mg}$ a.i./L was prepared similarly with commercial product, buprofezin 25\%WP $\left(\right.$ Applaud $\left.^{\circledR}\right)$. Control plots were treated with water containing the wetting agent. The test solution was applied by spray gun to a potted rice plant, and then the treated crop was kept in a greenhouse. Twenty nymphs of the third instar BPH were inoculated onto the treated rice plant on the predetermined days after treatment. The number of surviving nymphs was counted 7 days after each inoculation, and the corrected mortality was calculated in the same way as described in Section 2.2. The tests were conducted with two replications. In Tables 2 and 3, A-D indicate relative efficacy in comparison with buprofezin, as described below.

The period when the compound showed $80 \%$ or more corrected mortality was (A) longer (7 days or more) than that of buprofezin, (B) equal (within 6 days) to that of buprofezin, (C) shorter (7-13 days) than that of buprofezin, and (D) much shorter (14 days and more) than that of buprofezin.

\subsection{Comparison of BPH symptoms}

The symptoms of BPH affected by benzpyrimoxan were compared with those caused by buprofezin. Rice seedlings were cultivated in a paper pot until the 2.0-2.5 leaf stage in a greenhouse as a test crop. The candidate compound was formulated in $10 \%$ (w/w) SC, and a test solution of the compound at $50 \mathrm{mg}$ a.i./L was prepared by diluting an SC formulation with water containing a wetting agent $\left(\right.$ Mai-Rinoh $\left.{ }^{\circledR}, 0.1 \mathrm{~mL} / \mathrm{L}\right)$. That of the reference compound at $50 \mathrm{mg}$ a.i./L was prepared similarly with a commercial product, buprofezin 20\% SC (Applaud ${ }^{\circledR}$ ). Control plots were treated with water containing the wetting agent. The leaf sheaths and leaves of rice seedlings were dipped in the test solution for $30 \mathrm{sec}$ and allowed to dry. The treated seedlings were

Table 1. Insecticidal activity of phenyl pyrimidine derivatives against $\mathrm{BPH}$

\begin{tabular}{cccc} 
& $\mathrm{Y}$ & $\mathrm{LC}_{90}(\mathrm{mg}$ a.i./L) \\
\hline $\mathbf{N o}$ & $\mathrm{X}$ & $\mathrm{H}$ & $3-10$ \\
$\mathbf{2 a}$ & $\mathrm{OCF}_{3}$ & $\mathrm{OMe}$ & 0.3 \\
$\mathbf{7}$ & $\mathrm{OCF}$ & $\mathrm{OMe}$ & $>30$ \\
$\mathbf{8}$ & $\mathrm{Cl}_{3}$ & $\mathrm{OMe}$ & $>30$ \\
$\mathbf{9}$ & $\mathrm{CF}_{3}$ & $\mathrm{OMe}$ & $0.3-1$ \\
$\mathbf{1 0}$ & $t-\mathrm{Bu}_{2}$ & $\mathrm{OMe}$ & $0.1-0.3$ \\
$\mathbf{2 b}$ & $\mathrm{SiMe}_{3}$ & $\mathrm{OMe}$ & $0.03-0.1$ \\
Buprofezin & - & - & $0.3-1$ \\
\hline
\end{tabular}




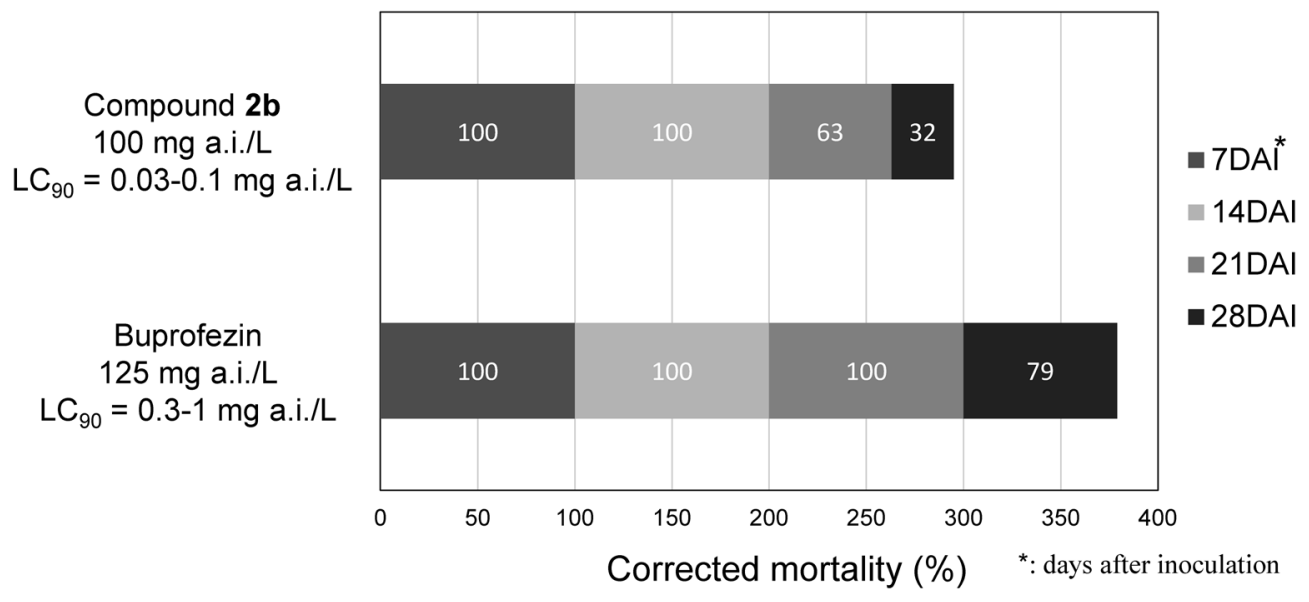

Fig. 2. Residual efficacy of the lead compound $\mathbf{2} \mathbf{b}$ against $\mathrm{BPH}$ in a greenhouse.

placed in a glass tube $20 \mathrm{~cm}$ long, and ten nymphs of the fourth instar $\mathrm{BPH}$ were inoculated onto the treated seedlings. The treated insects were maintained at $25 \pm 1^{\circ} \mathrm{C}, 60-70 \%$ R.H., and a $16 \mathrm{~L}$ : $8 \mathrm{D}$ photoperiod. Each treatment consisted of two replicates. Symptoms of the affected nymphs were observed 5 days after the treatment.

\section{Results and discussion}

\section{Biological activity of phenyl pyrimidine derivatives}

As shown in Table 1, compound $\mathbf{1}$ had high insecticidal activity against BPH; however, it was inferior to buprofezin. Further exploration was conducted to improve the insecticidal activity. Pyrimidine derivative $\mathbf{1}$ was comprised of three parts: a phenyl ring, a heterocyclic ring and substituents on a pyrimidine ring. As a result of the substituents' conversion on the pyrimidine ring, methoxy derivative 2a was found to exhibit more than ten times higher insecticidal activity than compound $\mathbf{1}$. Subsequently, optimization of the substituents on the phenyl ring moiety was conducted as described below.

The substituent on the pyrimidine ring was fixed to a methoxy group at the 5-position and the effect of substituent $\mathrm{X}$ was examined. Non-substituted derivative 7 and chloro derivative 8 showed low insecticidal activity. Trifluoromethyl derivative 9 and tert-butyl derivative $\mathbf{1 0}$ showed almost the same level of insecticidal activity as compound $\mathbf{2 a}$. In particular, the insecticidal activity of trimethylsilyl derivative $\mathbf{2 b}$ was much higher than that of buprofezin. These results suggested that substituent $\mathrm{X}$, being the lipophilic groups with a moderately hindered substituent, might be favorable for insecticidal activity. As a result of the above, compound $\mathbf{2} \mathbf{b}$ was selected as a lead compound.

\section{Residual efficacy of lead compound $\mathbf{2} \boldsymbol{b}$ against BPH}

Although the insecticidal activity of lead compound $\mathbf{2} \mathbf{b}$ was higher than that of buprofezin, its residual efficacy in a greenhouse was found to be insufficient (Fig. 2). Since sunlight with a wavelength of more than $290 \mathrm{~nm}$ reaches the earth, it is known that compounds with absorption in this wavelength range tend to have low photostability. ${ }^{7)}$ The maximum absorption wavelength $\left(\lambda_{\max }\right)$ of compound $\mathbf{2} \mathbf{b}$ was examined and confirmed to be $300 \mathrm{~nm}$, suggesting that its low residual efficacy might be derived from its physicochemical profile.

\section{Improvement of residual efficacy (lead optimization)}

The introduction of a linkage, $Z^{1}-Z^{2}$, was employed to improve the photostability by breaking the conjugated system of the biaryl structure. Since the tert-butyl derivatives were easier to convert than the trimethylsilyl derivatives, the linkage introduction was examined using the tert-butyl derivatives. The effects of various types of linkages are shown in Table 2. Non-linkage derivatives $\mathbf{2 b}$ and $\mathbf{1 0}$ showed high insecticidal activity. The introduction of a linkage tended to decrease the insecticidal activity (11, 12). Compound 13, having the oxymethylene linkage, exhibited the same level of insecticidal activity as non-linkage derivative 10. The residual efficacy of compound $\mathbf{1 3}$ was slightly superior

Table 2. Insecticidal activity and residual efficacy of pyrimidine derivatives against $\mathrm{BPH}$

\begin{tabular}{|c|c|c|c|c|}
\hline No. & $Z^{1}-Z^{2}$ & $\mathrm{X}$ & $\begin{array}{c}\mathrm{LC}_{90} \\
(\mathrm{mg} \text { a.i./L) }\end{array}$ & $\begin{array}{l}\text { Residual efficacy } \\
(100 \mathrm{mg} \text { a.i./L) }\end{array}$ \\
\hline 2b (lead compound) & none & $\mathrm{SiMe}_{3}$ & $0.03-0.1$ & $\mathrm{C}$ \\
\hline 10 & none & $t-\mathrm{Bu}$ & $0.1-0.3$ & $\mathrm{D}$ \\
\hline 11 & $\mathrm{O}$ & $t-\mathrm{Bu}$ & $0.3-1$ & $\mathrm{D}$ \\
\hline 12 & $\mathrm{CH}_{2}-\mathrm{O}$ & $t-\mathrm{Bu}$ & $>30$ & $\mathrm{D}$ \\
\hline 13 & $\mathrm{O}-\mathrm{CH}_{2}$ & $t-\mathrm{Bu}$ & $0.1-0.3$ & $\mathrm{C}$ \\
\hline 14 & $\mathrm{O}-\mathrm{CH}_{2}$ & $\mathrm{Cl}$ & $1-3$ & $\mathrm{D}$ \\
\hline 15 & $\mathrm{O}-\mathrm{CH}_{2}$ & $\mathrm{CF}_{3}$ & 0.3 & $\mathrm{C}$ \\
\hline Buprofezin & - & - & $0.3-1$ & $\mathrm{~B}^{*}$ \\
\hline
\end{tabular}

*: $125 \mathrm{mg}$ a.i./L 
Table 3. Effect of the substituents on the pyrimidine ring against $\mathrm{BPH}$

(Benzpyrimoxan)

*: $125 \mathrm{mg}$ a.i./L

to that of compound 10, which appeared to be due to the improved photostability $\left(\lambda_{\max }=\right.$ ca. $\left.260 \mathrm{~nm}\right)$. Interestingly, the residual efficacies of compounds $\mathbf{1 3}$ and $\mathbf{2 b}$ were at the same level, whereas the insecticidal activity of compound $\mathbf{1 3}$ was lower than that of lead compound $\mathbf{2} \mathbf{b}$. Although the effectiveness of the oxymethylene linkage to improve photostability was found, the residual efficacy of compound $\mathbf{1 3}$ was still insufficient compared to that of buprofezin. This result indicated that improvement of the insecticidal activity or physicochemical property besides photostability, such as volatility, was also required to improve the residual efficacy. Therefore, it was considered that further exploration of substituents on the phenyl ring and the pyrimidine ring was needed.

The effect of substituent $\mathrm{X}$ on the phenyl ring was investigated when the linkage was oxymethylene. This result was almost the same as those of the phenyl pyrimidine derivatives; that is, substituent $\mathrm{X}$, being the lipophilic groups with a moderately hindered substituent, seemed to be favorable for insecticidal activity $(13,14,15)$. The residual efficacy was not significantly improved by the conversion of substituent $\mathrm{X}$, while the (trifluoromethyl)benzyloxypyrimidine derivatives were found to give the most stable results in various laboratory tests (data not shown). For further exploration, the (trifluoromethyl)benzyloxy group was fixed and the effect of substituent $Y$ on the pyrimidine ring was examined.

Finally, the effect of substituent $Y$ at the 5-position of the pyrimidine moiety was examined (Table 3). Since substituent Y was widely convertible, various derivatives were synthesized. The $n$-propyloxy and sec-butyloxy derivatives (16 and 17) showed higher insecticidal activity than compound 15, and their residual efficacies were slightly superior or comparable to that of compound 15. Ethylthio derivative 18 showed moderate insecticidal activity. $n$-Butyl derivative 19 showed high insecticidal activity similar to the alkoxy derivatives (16 and 17), while its residual efficacy was insufficient. Cyclohexyl derivative 20 showed slightly higher residual efficacy than compound 19, though its insecticidal activity was inferior to that of compound 19. From these results, we focused on a cyclic group as substituent $Y$. The compound substituted with a cyclic group having two oxygen atoms $(\mathbf{2 1}, \mathbf{2 2})$ exhibited high residual efficacy. Notably, the residual efficacy of 1,3-dioxane derivative $\mathbf{2 1}$ was remarkable and superior to that of buprofezin. The vapor pressure of compound 21 was $1.39 \times 10^{-5} \mathrm{~Pa}\left(25^{\circ} \mathrm{C}\right)$, which was significantly lower than that of buprofezin $\left(1.25 \times 10^{-3} \mathrm{~Pa}\left(25^{\circ} \mathrm{C}\right)\right){ }^{8)}$ Therefore, it seemed that the low volatility of compound 21 contributed to the residual efficacy. Further optimization revealed that a 1,3-dioxanyl group substituted derivative, benzpyrimoxan, was selected for its insecticidal activity and residual efficacy.

\section{Symptoms of BPH nymphs treated with benzpyrimoxan versus buprofezin}

Figure 3 shows the symptoms of nymphs affected by benzpyrimoxan versus buprofezin. Although the nymphs affected by both compounds died at the time of molting, the dead nymphs treated with benzpyrimoxan turned blackish color compared to those treated with buprofezin and their exuviae were attached at the bottom of their bodies. This result indicated that the mode of action of benzpyrimoxan was the insect growth regulator, which is different from that of buprofezin.

\section{Conclusion}

We have discovered novel pyrimidine derivatives. Modifications of the substituents and introduction of the oxymethylene linkage and cyclic acetal groups led to benzpyrimoxan, which showed excellent insecticidal activity against nymphs of rice hoppers, including $\mathrm{BPH}$ strains resistant to existing insecticides. ${ }^{4)}$ Benzpyrimoxan will thus contribute to the combat strategy against insecticide resistance in rice cultivation area. Furthermore, it had

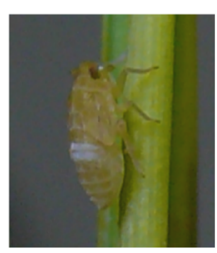

Control

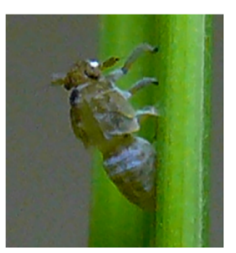

Buprofezin

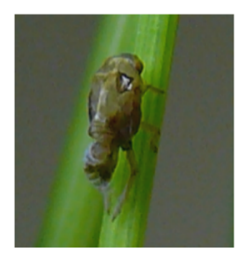

Benzpyrimoxan
Fig. 3. Symptoms of BPH nymphs 5 days after treatment. 
low adverse effects on pollinators and beneficial arthropods. ${ }^{4)}$ These features of the novel insecticide are expected to be suitable for use in IPM. Benzpyrimoxan was registered as Orchestra ${ }^{\circledR}$ SC and Orchestra ${ }^{\circledR}$ DL in Japan in September 2020 and is expected to contribute to society by ensuring a safe and steady food supply in the future.

\section{Acknowledgements}

We are deeply indebted to our colleagues at the Research Center, Nihon Nohyaku Co., Ltd., for their expert technical support in determining insecticidal activity. We also wish to express our thanks to Dr. T. Konno for his invaluable suggestions.

\section{References}

1) T. Toki, T. Koyanagi, M. Morita, T. Yoneda, C. Kagimoto and H. Okada: Jpn. Kokai Tokkyo Koho. JPH 06321903, 1994.

2) Willian, W. W., Linda, F. and Salvator, J. C: US. Pat. Appl. US 2002/0045634 (2002).

3) H. Kanno, M. Yasui, K. Ikeda and T. Harada: T. Jpn. Kokai Tokkyo
Koho. JPS 54003083 (1979).

4) E. Satoh, R. Kasahara, T. Aoki, K. Fukatsu, D. Venkata Ramanarao, H. Harayama, T. Murata and A. Suwa: Benzpyrimoxan: An insecticide for the control of rice plant hoppers. World Academy of Science, Engineering and Technology. International Journal of Agricultural and Biosystems Engineering. 11, 719-722 (2017).

5) E. Satoh, R. Kasahara, T. Aoki, K. Fukatsu, D. Venkata, Ramanarao, H. Harayama and T. Murata: "Recent Highlights in the Discovery and Optimization of Crop Protection Products (in press)", Elsevier, 2020.

6) E. Satoh, T. Murata, H. Harayama, N. Motofumi, K. Fukatsu, K. Inukai, R. Kasahara, Y. Abe, N. Hayashi and N. Fujita: PCT Int. Appl. WO 2013/115391 (2013).

7) S. Kagabu and S. Medej: Stability comparison of imidacloprid and related compounds under simulated sunlight, hydrolysis conditions, and to oxygen. Biosci. Biotechnol. Biochem. 59, 980-985 (1995).

8) H. Kanno, K. Ikeda, T. Asai and S. Maekawa: 2-tert-butylimino3-isopropyl-5-phenylperhydro-1,3,5-thiadiazin-4-one (NNI-750), a new insecticide. Proc. 1981 Br. Crop Prot. Conf. Pests Dis., pp. 59-66, 1981. 